\title{
Formulation and evaluation of analgesic activity of polysorbate 80-coated loperamide liposomes in mice
}

\author{
Irisappan Sarath Chandran ${ }^{1}$ and Pichandy Muthu Prasanna ${ }^{2 *}$ \\ ${ }^{1}$ P. Rami Reddy Memorial College of Pharmacy, Prakruthi Nagar, Utukur, Kadapa - 516003 , Andrapradesh, ${ }^{2}$ Research \\ Scholar, PRIST University, Thanjavur, Tamilnadu, India
}

*For correspondence: Email: muthuprasanna1000@rediffmail.com; Tel: +919908947749

\begin{abstract}
Purpose: To deliver loperamide ( $L p$ ) into mice brain using polysorbate 80 (PS80)-coated liposomes that inhibits $P$-glycoprotein $(P$-gp) efflux.

Method: $L p$ loaded liposomes were prepared by reverse phase evaporation technique using lecithin (Lec) and cholesterol (Ch). The efficacy of PS80-coated Lp liposomes (PLs) in mice was evaluated using central analgesic models (Eddy's hot plate method and tail immersion test) and peripheral analgesic model (acetic acid-induced writhing).

Results: PLs showed maximum possible response (MPR) of $58.33 \%$ at $60 \mathrm{~min}$ in Eddy's hot plate study. In the tail immersion test, PLs showed MPR of 67.64 and $69.24 \%$ at 60 and $90 \mathrm{~min}$, respectively, relative to control group. This confirms the potential of PLs to deliver $L p$ to the brain by inhibiting P-gp efflux. Dose response study using tail flick method confirmed the minimum Lp dose (25 $\mu \mathrm{g} / \mathrm{kg}$, i.v) required to achieve central analgesic activity using PLs.

Conclusion: PS80-coated Lp loaded liposomes (PLs) possess a good potential to inhibit P-gp efflux of $L p$ from brain, and also exhibit both central and peripheral analgesic activity.
\end{abstract}

Keywords: Loperamide, Polysorbate 80, P-glycoprotein (P-gp), Analgesic activity

Tropical Journal of Pharmaceutical Research is indexed by Science Citation Index (SciSearch), Scopus, International Pharmaceutical Abstract, Chemical Abstracts, Embase, Index Copernicus, EBSCO, African Index Medicus, JournalSeek, Journal Citation Reports/Science Edition, Directory of Open Access Journals (DOAJ), African Journal Online, Bioline International, Open-J-Gate and Pharmacy Abstracts

\section{INTRODUCTION}

Blood brain barrier (BBB) and cerebrospinal fluid barrier (CSFB) control the inflow of drug molecules into the brain. Lack of endothelial fenestrations and the presence of endothelial tight junctions enable BBB to restrict the drug transport into the central nervous system [1]. The BBB removes or effluxes most of the macromolecules unless specific carriers, transporters or receptors are present in the endothelial cells. Essential molecules such as glucose, amino acids and nucleosides are transported by specific proteins in the luminal surface of the endothelial cells and the transport of essential proteins and peptides to the brain are mediated by transcytosis $[2,3]$.

P-glycoprotein (P-gp) is a potent peptide in BBB which prevents any untoward drug or molecule entry in to the brain by its efflux nature [4]. Loperamide (Lp) is a morphine like opioid receptor agonist. Due to P-gp mediated efflux, Lp cannot enter into the brain thereby preventing its central analgesic activity. It acts on gastrointestinal $\mu$ and $\delta$ opiate receptors and reduces gastrointestinal motility [6]. Earlier research reported that $L p$ delivered by human serum albumin nanoparticle with adsorbed monoclonal antibody produces anti-nociceptive activity in tail flick test [7]. P-gp inhibitors such as 
indole alkaloids, quercitin, surfactants were also studied to assess their ability to facilitate BBB penetration [8].

Kreuter et al reported that the surfactant Polysorbate 80 (PS80) enabled the drug dalargin to reach brain by inhibiting P-gp efflux and produce anti-nociceptive activity [9]. PS80 adsorbs apolipoprotein- E globules over the drug to deliver it from the blood. PS80 mimics the carrier as LDL particle and LDL receptor recognize it as its ligand, favoring its entry in to brain by endocytosis [10]. Drugs such as tacrine, doxorubicin, hexapeptide and tubocurarine were also targeted using PS80 surfactant [12]

Thus PS80 adsorption or coating could help us in delivering loperamide to the brain. Liposome offers a great advantage of entrapping both hydrophilic and hydrophobic drug and its lipid constituents further promotes endocytosis through BBB. Its nano-sized dimension synergizes its brain targeting potential. Surface modification, antibody conjugation, stealthing etc. of liposomes makes it a potential carrier for brain targeting molecules [15].

Thus, in the present study, an attempt has been made to prepare PS80-coated Lp liposomes and evaluate its central analgesic activity.

\section{EXPERIMENTAL}

\section{Materials}

Polysorbate-80 was obtained from Sigma Aldrich and loperamide was received as a gift sample from Alembic Pharmaceutical, Vadodara, Gujarat. Lecithin, cholesterol and vitamin E were of analytical grade.

\section{Formulation of PS80 coated and uncoated Lp liposomes}

Lp loaded liposomes were prepared by "Reverse Phase Evaporation Technique" using lecithin (Lec) and cholesterol (Ch) with modification [16]. The lipids, Lec and $\mathrm{Ch}$, (in 9:1 ratio) were dissolved in diethyl ether. Drug solutions of Lp (5 $\mathrm{mL}, 2 \mathrm{mg} / \mathrm{mL}$ ) were prepared by dissolving $\mathrm{Lp}$ in chloroform along with $0.5 \mathrm{~mL}$ of vitamin $\mathrm{E}(0.6$ mole \%) to prevent lipid oxidation. Using the homogenizer (Tenbroeck tissue grinder country; operated at $5000 \mathrm{rpm}$, for $20 \mathrm{~min}$, at $50^{\circ} \mathrm{C}$ ) the solution was emulsified to form liposomal suspension with semi-solid gel like consistency until the chloroform evaporates. Any trace chloroform was evaporated using a vacuum evaporator (BUCHI EL 131 Rotavapor, Germany) under reduced pressure $(260-400 \mathrm{mmHg})$ at 60 ${ }^{\circ} \mathrm{C}$. The lipid gel was then collapsed and vortexed to attain fluid like consistency with addition of $10 \mathrm{~mL}$ phosphate buffer solution (PBS) and sonicated using a micro-tip probe sonicator(30 min; $40 \%$ frequency), (Vibra-Cell, Sonics and Materials, Inc., Danbury, CT, USA) forming multi-lamellar vesicles (MLV) in the liposomal suspension. PS80 coating was done by adding PS80 (2\%) drop wise in the MLV liposomal suspension with continuous magnetic stirring at 9000rpm; for $45 \mathrm{~min}$ followed by centrifugation $(75,000 \mathrm{~g}$ for $20 \mathrm{~min})$. The supernatant free Lp, excess PS80 and PEG were discarded. Trace oxygen was removed by flushing nitrogen gas and the PS80 coated MLVs (PLs) were lyophilized and stored at $4{ }^{\circ} \mathrm{C}$ for further study. Uncoated MLVs of loperamide (UL) were prepared as above but without the PS80. Blank PLs (BPLs) were prepared using the same protocol described above in the absence of $L p$.

Table 1: Control/Formulation and its content

\begin{tabular}{cc}
\hline Animal group & Content \\
\hline $\begin{array}{c}\text { Control } \\
\text { (1) Control }\end{array}$ & Animal receiving PBS (Phosphate Buffer saline) $(\mathrm{pH} 7.4)$ \\
$(2){ }^{*} \mathrm{Lp}$ & Animal receiving Lp drug $(3 \mu \mathrm{g} / \mathrm{mL})$ intrathecally in a volume of \\
& $10 \mu \mathrm{L}$ PBS through intrathecal catheter \\
(3) ${ }^{\$ L p}$ & Animal receiving Lp drug $(0.03 \mathrm{mg} / \mathrm{kg}, \mathrm{i} . \mathrm{v})$ intravenously \\
& through tail vein \\
Formulation & Animal receiving PS80 coated Lp Liposomes \\
PLs & Animal receiving Uncoated Lp liposomes \\
UL & Animal receiving Lp dispersed in 2 \% PS80 solution \\
PLp & Blank (PS80 coated liposomes without Lp) \\
BPLs & Naltrexone + PS80 coated Lp liposomes \\
NPLs &
\end{tabular}




\section{Experimental animals}

Healthy Swiss albino mice weighing $20-25 \mathrm{~g}$ of either sex were maintained under controlled conditions of temperature at $23 \pm 2{ }^{\circ} \mathrm{C}$, humidity $55-60 \%$ and a $12 \mathrm{~h}$ light-dark cycle. They were housed in sanitized polypropylene cages containing sterile paddy husk as bedding. They had free access to standard feed (standard commercial pellet diet) and water ad libitum. Experimental protocols were reviewed and approved by the Institutional Animal Ethics Committee - Committee for the Purpose of Control and Supervision of Experiments on Animals (CPCSEA), Prist University (Registration No. 292/CPCSEA/PHARMCEUT-11/06) and were performed in accordance with the National Institutes of Health guidelines for the care and use of laboratory animals(US) [29].

\section{Evaluation of analgesic activity}

\section{Eddy's hot plate method}

Eddy's hot plate method was to evaluate thermally-induced pain in mice. In this method mice were divided into eight groups (each group $n=10$ ). Mice in control group were injected with phosphate buffer solution $(2 \mathrm{~mL} / \mathrm{kg}, \mathrm{i} . \mathrm{v})$. Mice in ${ }^{*} \mathrm{~L} p$ group were injected with $10 \mu \mathrm{L}$ of intrathecal Lp formulation (3 $\mu \mathrm{g} / \mathrm{mL})$ [17] through intrathecal catheter and flushing with physiological saline $(0.9 \%)$ [18]. Mice in ${ }^{\$} \mathrm{Lp}$ group were injected with intravenous Lp formulation (0.03 mg/kg, i.v) [19] through tail vein. Mice in PLs group were injected with PS80 coated Lp Liposomes $(0.03 \mathrm{mg} / \mathrm{kg}$, i.v). Mice in UL group were injected with uncoated Lp liposomes $(0.03 \mathrm{mg} / \mathrm{kg}$, i.v). Mice in PLp and BPLs groups were injected with Lp dispersed in $2 \%$ PS80 solution and PS80 coated liposomes without $L p$ at the dose of $0.03 \mathrm{mg} / \mathrm{kg}$, i.v and $2 \mathrm{~mL} / \mathrm{kg}$, i.v respectively. NPLs group received Naltrexone $\mathrm{HCl}(0.1 \mathrm{mg} / \mathrm{kg}$, i.v $)$ along with PS80 coated Lp liposomes $(0.03 \mathrm{mg} / \mathrm{kg}$, i.v). Eddy's hot plate (Columbus Instruments, Columbus, $\mathrm{OH}$ ) maintained at $52{ }^{\circ} \mathrm{C}+0.5$ was used to evaluate response to thermal-induced pain. The "Maximum Possible Reaction Time" (MPR) of each mouse is the measure of hind paw withdrawal from the Eddy's hot plate (thermal withdrawal latency) and is the time interval between placement on the hot-plate and the first jump or lick of a hind limb. Animals with average baseline latency less than $25 \mathrm{~s}$ were used in this study. A cut-off latency of $30 \mathrm{~s}$ was followed to avoid tissue damage or thermal hyperalgesia [20]. The formulations and PBS were administered 30 min before the evaluation of thermal-induced pain and the MPR was recorded at $30,60,90$ and $120 \mathrm{~min}$.
The degree of analgesic activity was expressed as percentage of maximal possible response (MPR in \%), and was calculated as follows:

$$
\operatorname{MPR}(\%)=([\text { Test-Control] }) / \text { Test } X 100 \ldots \ldots(1)
$$

\section{Tail immersion test}

In this method the mice were divided into eight groups (each group $n=10$ ) and were prepared as explained above for the Eddy's hot plate technique. The lower $5 \mathrm{~cm}$ portion of each tail was immersed in a beaker of water maintained at $58 \pm 0.5{ }^{\circ} \mathrm{C}$. The cut off time of $20 \mathrm{~s}$ was maintained to avoid damage to the tail. The formulations and PBS were administered $30 \mathrm{~min}$ before the evaluation of tail immersion test and the MPR was recorded at 30,60, 90 and 120 min [9]. The degree of analgesic activity was expressed as percentage maximal possible response (MPR \%), and was calculated using equation 1.

\section{Acetic acid-induced writhing test}

In this method the mice were divided into eight groups (each group $n=10$ ) and were prepared as explained above for the Eddy's hot plate technique.

The formulations and PBS were administered 30 min before the acetic acid administration and the total number of writhing following intraperitoneal administration of acetic acid solution (1\% v/v in normal saline, $10 \mathrm{~mL} / \mathrm{kg}$ ) was recorded over a period of 10 min, starting 5 min after acetic acid injection [22]. The percentage protection was calculated according to the equation 1 .

\section{Dose-response studies}

Based on the result of in vivo studies, PLps was selected due to its effective central analgesic activity for determining the minimum Lp dose required for maximum MPR\% response. Lp concentrations ranging from $5 \mu \mathrm{g} / \mathrm{kg}$ (6 times less from the IV Lp dose) to $40 \mu \mathrm{g} / \mathrm{kg}$ were selected. Lp equivalent to $5,10,15,20,25,30$, 35 and $40 \mu \mathrm{g} / \mathrm{kg}$ loaded in PLs were administered to animals by IV and observed for its analgesic activity by tail immersion test [23]. The response was plotted as MPR\% as described above and curve was constructed (Figure 1).

\section{Statistical analysis}

The data for analgesic activity was expressed as mean \pm standard deviation (SD). Statistical 
analysis was carried out using one-way ANOVA followed by Tukey's t-test. Differences were considered significant at $p \leq 0.05$.

\section{RESULTS}

\section{Analgesic activity}

The MPR\% of various formulations and PBS are shown in Table 1. The response time for all the observations for both Eddy's hot plate and tail immersion test was $2 \mathrm{~h}$. A base line response was recorded for PBS treated mice in control group. In Eddy's hot plate method *Lp showed maximum MPR\% at $1 \mathrm{~h}(60.22 \%)$ followed by PLs (58.33 \%).

Tail immersion test also reflected the same response with higher MPR\% at $1 \mathrm{~h}$ for ${ }^{*} \mathrm{Lp}$ (73.21 $\%)$ followed by PLs (67.64 \%). Intrathecal delivery of $L p\left({ }^{*} L p\right)$, delivered the drug directly to brain eliciting analgesic effect of $L p$ over this noxious thermal stimulus. PLs also exhibited $67.64 \%$ and $69.24 \% \mathrm{MPR}$ at $60 \mathrm{~min}$ and $90 \mathrm{~min}$ respectively, which are comparable with that of ${ }^{*}$ Lp group but not as effective as that of * Lp.

In Eddy's hot plate, though ${ }^{\$} \operatorname{Lp}(15.41 \%)$ and UL $(14.62 \%)$ showed some increase in MPR \%, but it was negligible considering their respective basal normal values. NPLs, PLp and BPLs showed very low or negligible rise of MPR \% both in Eddy's hot plate and tail immersion test.

In acetic acid induced writhing study (Table 3 ), * Lp showed significant decrease $(p<0.001)$ in the number of writhing and the protective effect was $81.94 \%$. The PS80 coated liposomal formulation (PLs) was also found to reduce the no. of writhing significantly $(p<0.001)$ and the protective effect was $75.30 \%$. Uncoated liposomes (UL) showed writhing inhibition of about $13.96 \%$. Blank PLs (BPLs) and ${ }^{\$}$ Lp showed very low inhibition. The effect of naltrexone was prominent in this writhing inhibition study which showed very negligible percentage of writhing inhibition (4.38\%) and this would be attributed to its antagonistic property against the drug Lp in the brain, delivered by PLs.

\section{Dose response study}

Dose response study of PLs (Figure 1) gave a sigmoidal curve. The dose of $25 \mu \mathrm{g} / \mathrm{kg} \mathrm{Lp}$ produced max MPR (58.42 \%). With further increase of dose to 30,35 and $40 \mu \mathrm{g} / \mathrm{kg}$, a plateau was observed, indicating no further increase in MPR. This sigmoidal curve shows that the minimum effective dose of $L p$ in PLs formulation is $25 \mu \mathrm{g} / \mathrm{kg}$ for maximum analgesic activity.

Table 2: Analgesic activity of different Lp formulation using Eddy's hot plate and Tail immersion test in mice

\begin{tabular}{|c|c|c|c|c|c|c|c|c|}
\hline \multirow[t]{2}{*}{ Group } & \multicolumn{3}{|c|}{ MPR (\%, Eddy's hot plate) } & \multicolumn{4}{|c|}{ MPR (\%,Tail immersion) } & \multirow[b]{2}{*}{$120 \mathrm{~min}$} \\
\hline & $30 \mathrm{~min}$ & $60 \mathrm{~min}$ & $90 \min$ & $120 \mathrm{~min}$ & $30 \mathrm{~min}$ & $60 \mathrm{~min}$ & $90 \mathrm{~min}$ & \\
\hline $\mathrm{C}$ & 0 & 0 & 0 & 0 & 0 & 0 & 0 & 0 \\
\hline${ }^{*} \mathrm{Lp}$ & 57.33 & 60.22 & 59.21 & 44.23 & 69.32 & 73.21 & 71.25 & 54.85 \\
\hline PLs & 53.21 & 58.33 & 55.33 & 38.22 & 65.45 & 67.64 & 69.24 & 48.38 \\
\hline$\$$ Lp & 14.11 & 15.41 & 15.24 & 8.28 & 3.55 & 4.20 & 5.10 & 2.52 \\
\hline UL & 17.21 & 14.62 & 16.57 & 12.54 & 5.11 & 6.21 & 4.22 & 2.54 \\
\hline PLp & 4.51 & 5.10 & 4.84 & 3.44 & 1.88 & 2.04 & 2.22 & 1.34 \\
\hline BPLs & 3.44 & 2.84 & 3.45 & 2.82 & 2.11 & 3.54 & 2.57 & 1.57 \\
\hline NPLs & 2.45 & 4.22 & 5.41 & 3.54 & 4.22 & 4.58 & 5.21 & 3.54 \\
\hline
\end{tabular}

Table 3: Analgesic activity of different Lp formulation determined in acetic acid induced writhing test in mice

\begin{tabular}{|c|c|c|c|}
\hline Group & Formulation & No. of writhings & Writhing inhibition (\%) \\
\hline $\mathrm{C}$ & PBS & $68.24 \pm 2.54$ & -- \\
\hline${ }^{*} \mathrm{Lp}$ & Intrathecal administered drug (Lp) & $12.32 \pm 3.61^{* * \star}$ & 81.94 \\
\hline PLs & PS80 coated Liposomes & $16.85 \pm 0.28^{* * *}$ & 75.30 \\
\hline UL & Uncoated Liposomes & $56.44 \pm 1.40$ & 17.29 \\
\hline${ }^{\$} \mathrm{Lp}$ & Intravenous administered drug (Lp) & $54.45 \pm 3.54$ & 20.20 \\
\hline PLp & Drug (Lp) dispersed in $2 \%$ PS80 & $64.54 \pm 2.84$ & 5.45 \\
\hline BPLs & Blank PLs (without drug Lp) & $67.34 \pm 3.47$ & 1.31 \\
\hline NPLs & Naltrexone + PLs & $65.25 \pm 3.57$ & 4.38 \\
\hline
\end{tabular}

Values are expressed as mean $\pm S D, n=10 ;{ }^{* * *} p<0.001$ considered significant as compared to control 


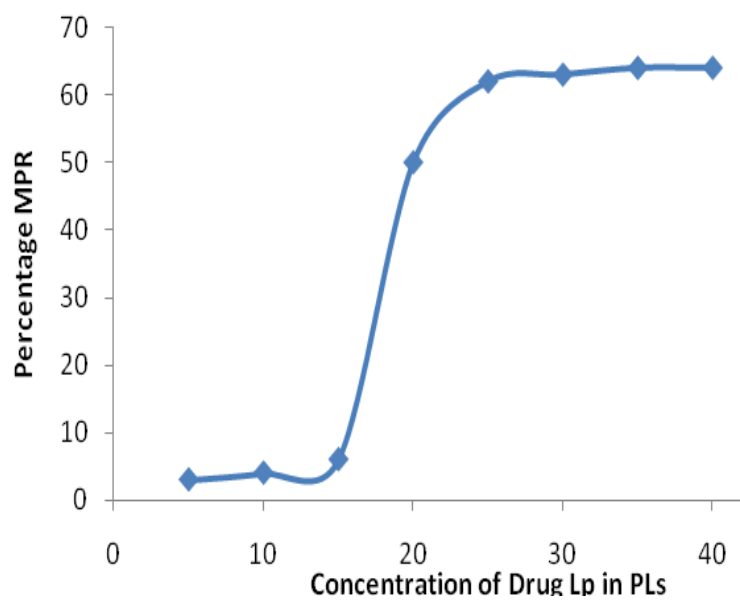

Figure 1: Dose response curve of Lp following i.v. administration of various doses of PLs formulation $(n=$ 3)

\section{DISCUSSION}

Our results have shown the potential analgesic effect of PLs in both Eddy's hot plate and tail immersion tests. This substantiates positive delivery of loaded Lp byPS80 coated liposome.

Naltrexone is an opioid antagonist which displaces the opioid agonist from receptors binding site. In both central analgesic models when naltrexone was given along PLs, it showed very low or negligible rise of MPR\% and is probably due to the displacement of centrally delivered $L p$ from the opiod receptors. This confirms the presence of $L p$ receptors in the brain and any rise in pain threshold was only by central Lp action and not by peripheral mechanisms [24]. Therefore, NPLs provide substantial evidence for the presence of $L p$ in the mouse brain.

The acetic acid induced abdominal constriction (writhing test) has been widely used for evaluating analgesic screening [22]. Intraperitoneal administration of acetic acid showed abdominal constriction resulting in stretching of hind limbs known as writhing response [25]. Pain sensation in this writhing method is triggered by local inflammatory response resulting in the release of free arachidonic acid, prostaglandins and other mediators into the peritoneum which in turn stimulate nociceptive neurons [26]. This writhing response can be counteracted by CNS opiate receptor agonist. In this study, *Lp and PS80 coated liposomal formulation (PLs) was found to reduce the number of writhing significantly.

In some studies, it has been reported that coating of nanoparticles with PS80, which adsorbs apolipoproteins, enables the liposomes to penetrate the BBB [27]. Thus, the analgesic effect of PLs could be due to the presence of PS80. However, further research is needed to confirm this finding. But still further research is needed to find reasons behind the analgesic effects of PLs

\section{CONCLUSION}

The findings of this study show that PS 80 coating has a fair potential of inhibiting P-gp efflux for delivery of $L p$ to brain and exhibits central and peripheral analgesic activity. The lipid-based delivery (PLs) with PS80 coat would help endocytic uptake transcytosis across BBB. This novel approach can further be explored for many potential drugs which face BBB restrictions.

\section{DECLARATIONS}

\section{Acknowledgement}

The authors are thankful to the PRIST University, Tamilnadu, India for providing support for this research work.

\section{Conflict of Interest}

No conflict of interest associated with this work.

\section{Contribution of Authors}

The authors declare that this work was done by the authors named in this article and all liabilities pertaining to claims relating to the content of this article will be borne by them.

\section{Open Access}

This is an Open Access article distributed under the terms of the Creative Commons Attribution License, which permits unrestricted use, distribution, and reproduction in any medium, provided the original work is properly credited.

\section{REFERENCES}

1. Graff CL, Pollack GM. Drug transport at the blood-brain barrier and the choroid plexus. Curr Drug Metab 2004; 5: 95-108.

2. Abbott NJ, Ronnback L, Hansson E. Astrocyteendothelial interactions at the blood-brain barrier. Nat Rev Neurosci 2006; 7: 41-53.

3. Neuwelt EA. Mechanisms of disease: the blood-brain barrier. Neurosci 2004; 54: 131-140. 
4. Schinkel AH, Wagenaar E, van Deemter L, Mol CA, Borst $P$. Absence of the MDR1a P-glycoprotein in mice affects tissue distribution and pharmacokinetics of dexamethasone, digoxin, and cyclosporin A. J Clin Invest 1995; 96: 1698-1705.

5. Mackerer CR, Clay G A, Dajani EZ. Loperamide binding to opiate receptor sites of brain and myenteric plexus. $J$ Pharmacol Exp Ther1976; 199: 131-140.

6. Ulbrich $K$, Knobloch $T$, Kreuter J. Targeting the insulin receptor: nanoparticles for drug delivery across the blood-brain barrier (BBB).J Drug Trg 2011; 19: 125-132.

7. Varma MV, Ashokraj Y, Dey CS, Panchagnula R. Pglycoprotein inhibitors and their screening: $A$ perspective from bioavailability enhancement. Pharmacol Res 2003; 48: 347-359.

8. Kreuter J, Petrov VE, Kharkevich DA, Alyautdin RN. Influence of the type of surfactant on the analgesic effects induced by the peptide dalargin after its delivery across the blood-brain barrier using surfactant-coated nanoparticles. J Control Rel 1997; 49: 81-87.

9. Kandadi P, Syed MA, Goparaboina S, Veerabrahma K, $K i s h a n V$. Tween 80 containing lipid nanoemulsions for delivery of indinavir to brain. Acta Pharm Sinica B 2013, 3: 345-353.

10. Alyautdin RN, Tezikov EB, Ramge $P$, Kharkevich DA, Begley DJ, Kreuter J. Significant entry of tubocurarine into the brain of rats by absorption to polysorbate 80coated polybutylcyanoacrylate nanoparticles: an insitu brain perfusion study. J Microencapsul 1998; 15: 67-74.

11. Heath TD, Macher BA, Papahadjopoulos D. Covalent attachment of immunoglobulins to liposomes via glycosphingolipids. Biochem Biophys Acta 1981; 640 : 66-81.

12. Szoka Jr F, Papahadjopoulos D. Procedure for preparation of liposomes with large internal aqueous space and high capture by reverse-phase evaporation. Proc Natl Acad Sci 1978; 75: 4194-4198.

13. Kumar R, Reetaa KH, Ray SB. Antinociceptive effect of intrathecal loperamide: role of mu-opioid receptor and calcium channels. Eur J Pharmacol 2012; 696: 77-82.
14. Schinkel AH. P-glycoprotein, a gatekeeper in the bloodbrain barrier. Adv Drug Del Rev 1999; 36:179-194.

15. Sohji Y, Kawashima K, Shimizu M. Pharmacological studies of loperamide, an anti-diarrheal agent II. Effects on peristalsis of the small intestine and colon in guinea pigs. Nihon Yakurigaku Zasshi. 1978; 74: 155-163.

16. Minville V, Laffosse JM, Fourcade O, Girolami JP, Tack I. Mouse model of fracture pain. Anesthesiol 2008; 108: 467-472.

17. Vongtau HO, Abbah J, Ngazal IE. Anti-nociceptive and anti-inflammatory activities of the methanolic extract of Parinari polyandra stem bark in rats and mice. $J$ Ethnopharmacol2004; 90: 115-121.

18. Boehm CA, Carney EL, Tallarida RJ, Wilson RP. Midazolam enhances the analgesic properties of dexmedetomidine in the rat. Vet Anaesth Analg 2010; 37: $550-556$.

19. Chung C, Carteret AF, McKelvy AD, Ringkamp M, Yang F, Hartke TV, Dong X, Raja SN, Guan Y. Analgesic properties of loperamide differ following systemic and local administration to rats after spinal nerve injury. Eur J Pain 2012: 16: 1021-1032.

20. Amico RM, Caruso A, Trombadore S, Scifo R, Scapagini $U$. Gangliosides antinociceptive effects in rodents. Arch Int Pharmacodyn Ther 1984; 272: 103-117.

21. Hunskaar $S$, Hole $K$. The formalin test in mice: dissociation between inflammatory and noninflammatory pain. Pain1987; 30: 103-114.

22. Elkiweri IA, Zhang YL, Christians U, Ng KY, Tissot van Patot MC, Henthorn TK. Competitive substrates for $P$ glycoprotein and organic anion protein transporters differentially reduce blood organ transport of fentanyl and loperamide: pharmacokinetics and pharmacodynamics in Sprague-Dawley rats. Anesth Analg 2009; 108: 149-159.

23. Ramge $P$, Unger RE, Oltrogge $B$, Zenker $D$, Begley $D$, Kreuter J, von Briesen $H$. Polysorbate-80 coating enhances uptake of polybutylcyanoacrylate (PBCA)nanoparticles by human and bovine primary brain capillary endothelial cells. Eur J Neurosci 2000; 12: 1931-1940 